Chirurgia (2017) 112: 320-325

No. 3, May - June

Copyright $\odot$ Celsius

http://dx.doi.org/10.21614/chirurgia.112.3.320

\title{
State of the Art of Intraoperative Ultrasound in Liver Surgery: Current Use for Resection-guidance
}

\author{
Guido Torzilli, Fabio Procopio
}

Department of Surgery \& Division of Hepatobiliary \& General Surgery, Humanitas University, Humanitas Research Hospital, IRCCS Milan, Italy

Corresponding author:

Guido Torzilli, MD, PhD, FACS

Professor of Surgery, Director Department of Surgery \& Division of Hepatobiliary \&

General Surgery, Humanitas University, Humanitas Research Hospital - IRCCS,

Via Manzoni 56, 20089, Rozzano, Milan, Italy E-mail: ricercachirurgia.epatobiliare@humanitas.it

Received: 6.05 .2017

Accepted: 19.05.2017

\section{Rezumat}

Ecografia intraoperatorie de ultimă generatie în chirurgia hepatică: utilizare pentru rezectia sub ghidaj imagistic

Realizarea intervențiilor chirurgicale hepatice fără o strategie pentru protejarea parenchimului prezintă riscuri semnificative pentru supraviețuirea pacientului din cauza incidenței ridicate de insuficiență hepatică postoperatorie. În chirurgia hepatică modernă, utilizarea ecografiei intraoperatorii permite desfăşurarea aşa zisei "chirurgii radicale dar conservative", un factor esențial pentru vindecarea unui procent ridicat de pacienți, care până acum câțiva ani aveau o singură opțiune: îngrijirea paliativă. Prezentul articol detaliază motivația pentru folosirea ecografiei intraoperatorii pentru rezecția sub ghidaj imagistic.

Cuvinte cheie: ecografie intraoperatorie, rezecție hepatică, hepatectomie

\section{Abstract}

The performance of hepatic surgery without a parenchyma-sparing strategy carries significant risks for patient survival because of the not negligible occurrence of postoperative liver failure. In the modern liver surgery the use of the intraoperative ultrasound (IOUS) allows the performance of the so-called "radical but conservative surgery", which is the pivotal factor to offer a chance of cure to an increasing proportion of patients, who until few years ago were considered only for palliative care. The present article details the rationale of IOUS for resection-guidance in liver surgery.

Key words: intraoperative ultrasound, liver resection, hepatectomy 


\section{Introduction}

In the modern liver surgery the use of the intraoperative ultrasound (IOUS) includes the staging of the liver disease and more importantly the resection-guidance. Whether in patients with hepatocellular carcinoma (HCC) or in patients with colorectal liver metastasis (CLM), IOUS allows the performance of the so-called 'radical but conservative surgery' (1), which is the pivotal factor to offer a chance of cure to an increasing proportion of patients, who until few years ago were considered only for palliative care. Indeed, in the last decade the definition of resectability has moved from a focus on tumor characteristics, such as tumor number and size, to determination of whether both intrahepatic and extrahepatic disease can be completely resected, and whether such an approach is appropriate from an oncologic standpoint.

Starting from the technical requirements, this article describes the current use of IOUS in liver surgery.

\section{Technical Requirements}

Generally, high-frequency probes (7.5 to 10 $\mathrm{MHz}$ ) are recommended to perform IOUS, because they allow a higher spatial resolution than those that operate at lower frequencies (3.5 to $5 \mathrm{MHz}$ ). However, based on the authors' experience operating an exploration with low frequencies is very useful, especially at the beginning of the liver exploration, since they allow an overall view of the liver, which is essential for the general anatomy exploration. Moreover, the higher spatial resolution at the superficial portion of the liver may be less important than the overall visibility of the deeper structures, because the most superficial portions are also those appreciable with palpation. However, the most recent IOUS probes are multi-frequencies probes that can be set up based on the patient characteristics. The ideal probe should be minimal in size, with the aim to be handled in narrow spaces, but at the same time it should be stable and large enough to give the widest scanning area. Fig. 1 shows the IOUS probes we usually use.

\section{Technique of Exploration}

The liver exploration should always start with the inspection and palpation of the organ together with the entire peritoneal cavity. This should not be avoided in favor of IOUS, because as recently demonstrated the inspection and palpation of the liver still play a significant role (2) Once into the peritoneal cavity, the liver mobilization starts with the division of the round and falciform ligaments to get the space to handle the probe. The ultrasound system should be placed in front of the first operator then opposite to his working-side respect to the patient, for allowing himself, who should be the one performing the IOUS, to simultaneously view the screen and the operative field. Indeed, the information gathered during the exploration requiresdirect interpretation to be most profitable in impacting the surgical strategy. Hard and irregular surface of the liver, as in case of cirrhosis and scars, make difficult the performance of IOUS. In such a case having different probes with different shapes makes the differences. Besides, the mobilization of the liver may give more space to put the probes in a different scanning plane, which hopefully do not include scars or irregular surfaces. In general, the liver may be scanned following the glissonian pedicles and the hepatic veins. However, the precise segmental anatomy requires the identification of the glissonian pedicles rather than the hepatic veins.

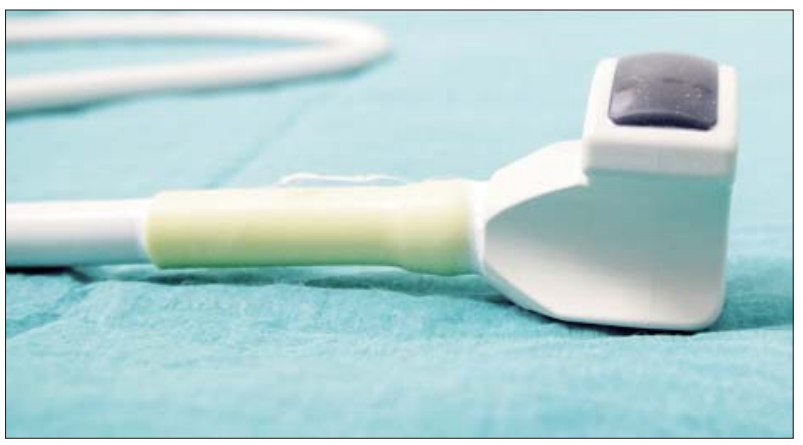

Figure 1. This picture shows the probe used for ultrasound guidance feature by a convex scanning area, ensuring a minimal space occupation and a large scanning window, and an ergonomic shape for fingertips allocation and optimal handling 


\section{Resection-guidance}

IOUS is essential to guide the resection although its reported impact varies among the published series depending on the type of the liver tumors considered and more importantly on the surgical policy applied (1,3-6). The more conservative is the surgery the more profitable is the impact of IOUS.

In general, using IOUS the surgeon may understand in a three-dimensional fashion the relationships between the tumor and the intrahepatic bilio-vascular structures with the aim to tailor the resection to be radical but conservative $(7,8)$. In most of the patients, especially in those patients with complex tumoral presentation, a wide exposition of the surgical field is essential. This means a full liver mobilization from the diaphragmatic ligaments and from the inferior vena cava (IVC) (Fig. 2). We usually use a J-shaped laparotomy, which can be extended in a thoraco-phreno-laparotomyin cases of tumors located in segments 1 , 4-superior, 7, and 8 as well as in redo-hepatectomy, narrow thoracic cage or obese patients (9). The aim of such a wide exposition is to get enough space to put the surgeon's left hand behind the right hemiliver to handle the organ and particularly the portion of the liver, which is going to be removed in a conservative fashion. Following the principle of the radical but conservative surgery, we defined some criteria to manage the situation of a tumor in contact with a glissonean pedicle or a hepatic vein branch reporting original surgical IOUS-guided techniques (10). The two strongholds of these techniques are anyhow the preservation of maximizing the preservation of the glissonean pedicles, and minimizing the parenchyma sacrifice despite resection of one or more hepatic vein (11). These two targets rely on the following:

\section{Preserving the Liver Skeleton}

The glissonian pedicles can be considered a sort of liver skeleton which if amputated imply the removal of the surrounding liver parenchyma. Therefore their sparing even when in contact with a tumor means parenchyma-sparing $(10,12)$. Data shows that the risk of local recurrence is not increased for HCC (13). More recently we have demonstrated that this is true also for colorectal metastases (CLM) (14) when detachment is feasible. Tumor exposure in these circumstances has been classified as R1vasc, and the related recurrence risk seems similar to that of R0.

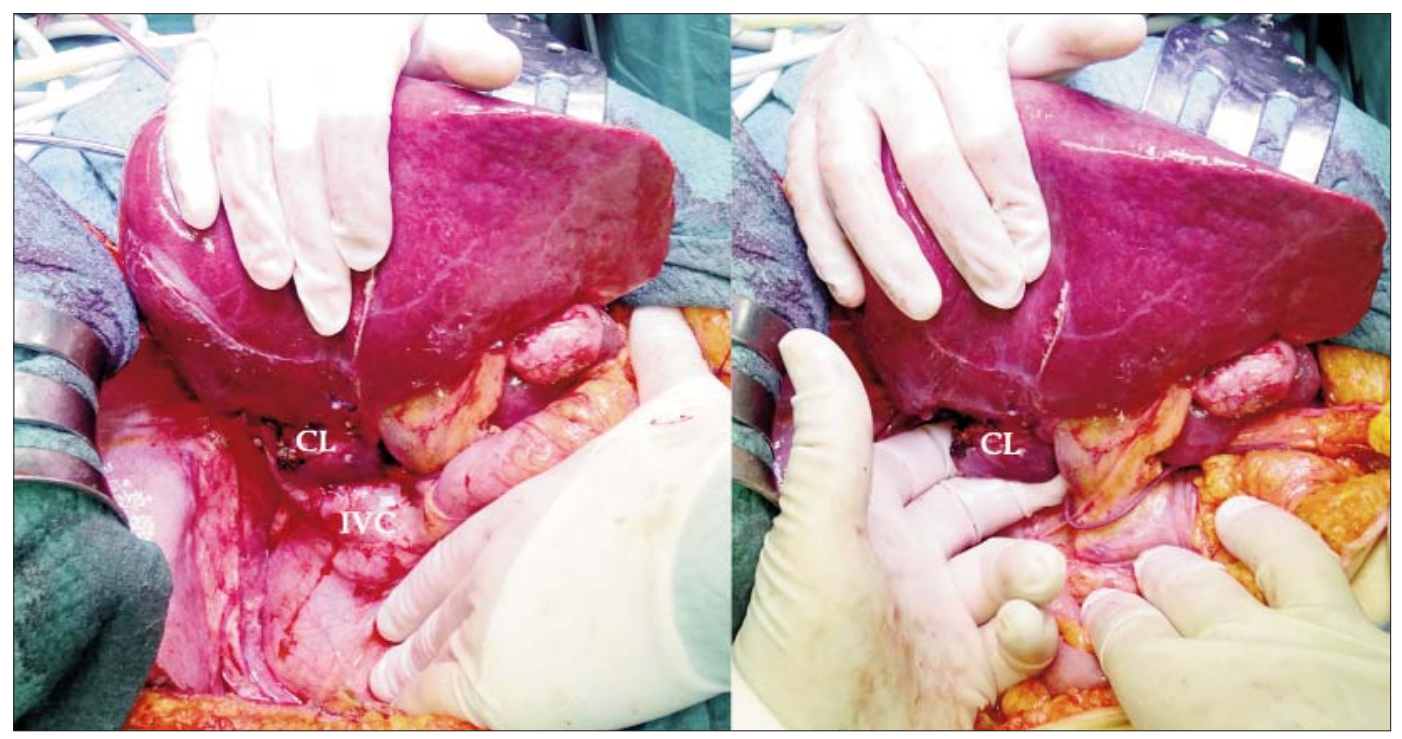

Figure 2. This picture shows the IOUS appearance of a communicating vein connecting the right hepatic vein $(\mathrm{RHV})$, infiltrated by the tumor $(\mathrm{T})$, with the middle hepatic vein (MHV) 


\section{Warranting the Outflow}

The hepatic vein as for the glissoneans pedicles may be spared when just in contact with the tumor at IOUS (15). However, hepatic vein resection even at caval confluence does not imply extension of the hepatectomy. Indeed, if accessory veins as an inferior right hepatic vein (IRHV) (16) or communicating veins (CV) (17) are present (Fig. 3), parenchyma sparing can be warranted anyway. CVs exist in the vast majority of tumor compressing or occluding one of more hepatic vein at caval confluence, and provoking in that a sort of secondary BuddChiari Syndrome. The detection and respect of these CVs allows the resection of the hepatic vein in a parenchyma-sparing way by shunting the blood outflow to the adjacent hepatic vein.

\section{New Operations}

Following the aforementioned criteria, authors have minimized the rate of major hepatectomy devising and standardizing new procedures (10), as the Systematic Extended Right Posterior Sectionectomy (SERPS) (5) and the Mini Upper Trasversal Hepatectomy (18) as alternatives to right hepatectomy, the Upper Trasversal Hepatectomy (UTH) as an alterative to trisectionectomies or unresectability for tumor involving at caval confluence two (left or right UTH) or even all the 3 hepatic veins (total UTH) (10,19), the Mini-mesohepatectomy $(\mathrm{MMH})$ as an alternative to central hepatectomy or trisectionectomies (6), the Liver Tunnel preserving or not the middle hepatic vein, for tumors involving segments 1, 4s, 8 (20) (Fig. 4). All these new operations have been associated with limited resections or combined themselves each other to allow the removal of multiple bilobar CLM with the intent of offering tumor clearance in a single session despite the advancement of the liver involvement rather than in a staged perspective. Other than the reduced surgical risk compared to techniques such as the two stage hepatectomy (21) or more recently the liver partitioning (22) preserving the liver parenchyma and consequently the aforementioned liver skeleton allows a high rate

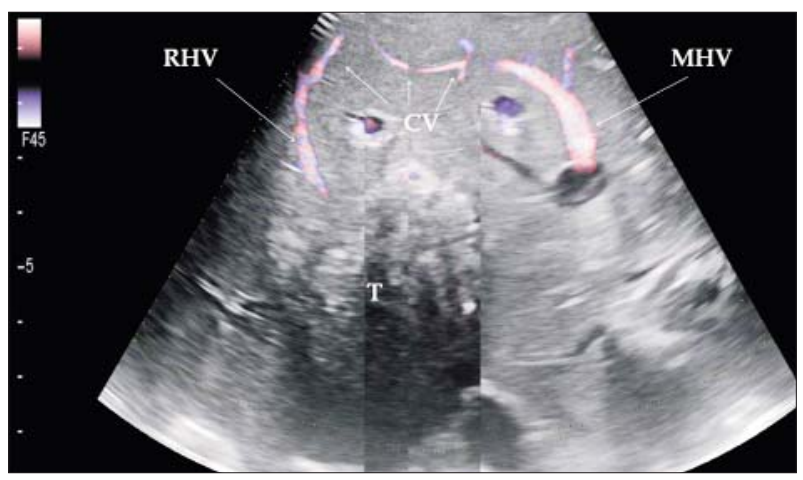

Figure 3. This picture shows the full mobilization of the liver from the inferior vena cava (IVC); CL: caudate lobe

of redo surgery in case of relapse (23), which on the other hand is not higher than after the staged procedures (24). In the event of HCC the oncological needs would demand the removal of the surrounding liver parenchyma in an anatomical fashion. The latter would require usually the removal of a large amount of liver parenchyma unless it could be suitable the removal of just the segment or subsegment in which the tumor is located, which would be preferable especially in patients with diseased liver as those carrier of HCC generally are. For this purpose the first procedure described was

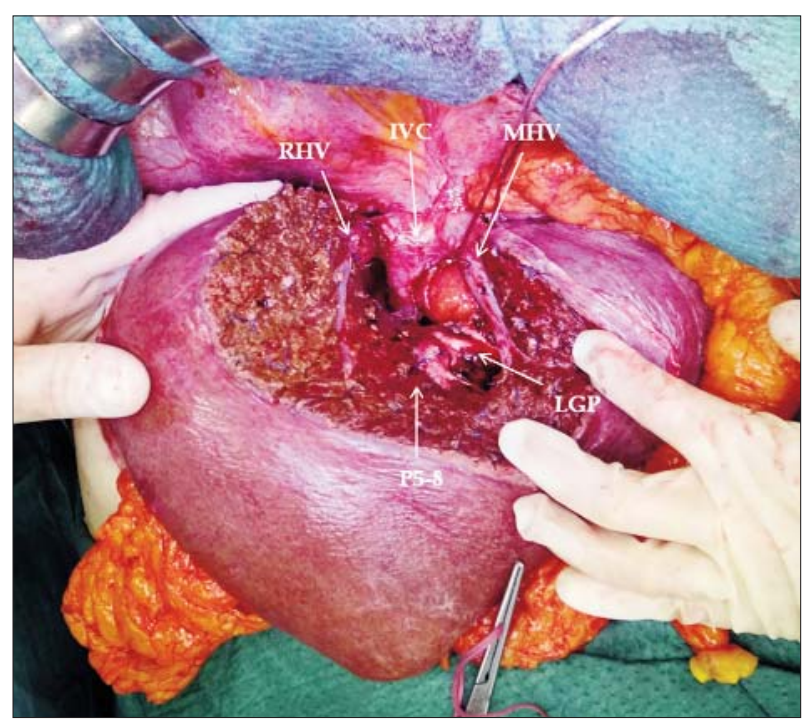

Figure 4. This picture shows the liver cut surface after a liver tunnel; IVC inferior vena cava; LGP left glissonean pedicle; MHV middle hepatic vein; P5-8 glissonean pedicle for the right anterior section; RHV right hepatic vein 
the so-called systematic segmentectomy devised in early 1980s (25), which consists in the puncture of the portal branch feeding the tumor, in the injection of dye in itself, followed by the removal of the demarcated area. That just described remains the most precise method for segmental and subsegmental anatomical demarcation. Its main drawback, other than the quite high skill in puncturing millimetric vessels, is the fact that if the ink regurgitates or is injected into the wrong portal branch, it could be difficult to identify the proper area to be removed. Another technique is represented by the compression of the glissonean pedicle afferent to the tumor. Initially used for tumors located in the left hemiliver (26), more recently it has been successfully extended its application to any segment (27), including the segment 8, and even to sectional portion of the liver (28). Once the feeding portal branch is identified at IOUS, it can be compressed using the IOUS probe by one side of the liver and the finger by the opposite side with the aim to induce a transient ischemia of the portion of the liver distally to the compression site. This portion can then be marked with the electrocautery, the compression is released, and the resection is carried out. This technique is simple, fast, not invasive and reversible. Moreover, the possibility to modify the site of compression and then the resection volume allows tailoring the resection in function of the tumor features, and the status of the background liver.

\section{Conclusions}

In conclusions, IOUS guidance allows expanding indications by offering the chance of cure to a greater proportion of patients, otherwise excluded from the surgical program or submitted to more traditional but more risky operations. This is the case of patients carrying ill-located tumors in contact with major intrahepatic vessel who could receive IOUS-guided parenchymasparing resection instead of staged procedures and even being judged unresectable. This approach relies on the detachment of tumors from vessels and the identification of $\mathrm{CVs}$ among hepatic veins. For HCC the possibility to address conservative anatomic resections enable a more conservative but still oncologically suitable surgical treatment for patients generally carrier of diseased livers. Provided the related technical issues, which should be spread among the specialized surgical community, parenchymasparing procedures and their indications can nowadays being standardized and reproduced.

\section{References}

1. Torzilli G, Montorsi M, Donadon M, Palmisano A, Del Fabbro D, Gambetti $A$, et al. "Radical but conservative" is the main goal for ultrasonography-guided liver resection: prospective validation of this approach. J Am Coll Surg. 2005;201(4):517-28.

2. Hata S, Imamura H, Aoki T, Hashimoto T, Akahane M, Hasegawa K, et al. Value of visual inspection, bimanual palpation, and intraoperative ultrasonography during hepatic resection for liver metastases of colorectal carcinoma. World J Surg. 2011;35(12):2779-87. doi: 10.1007/s00268-011-1264-7.

3. Cerwenka H, Raith J, Bacher H, Werkgartner G, el-Shabrawi A, Kornprat $\mathrm{P}$, et al. Is intraoperative ultrasonography during partial hepatectomy still necessary in the age of magnetic resonance imaging? Hepatogastroenterology. 2003;50(53):1539-41.

4. Jarnagin WR, Bach AM, Winston CB, Hann LE, Heffernan N, Loumeau $\mathrm{T}$, et al. What is the yield of intraoperative ultrasonography during partial hepatectomy for malignant disease? J Am Coll Surg. 2001; 192(5):577-83.

5. Torzilli G, Donadon M, Marconi M, Botea F, Palmisano A, Del Fabbro D, et al. Systematic extended right posterior sectionectomy: a safe and effective alternative to right hepatectomy. Ann Surg. 2008;247(4):603-11. doi: 10.1097/SLA.0b013e31816387d7.

6. Torzilli G, Palmisano A, Procopio F, Cimino M, Botea F, Donadon M, et al. A new systematic small for size resection for liver tumors invading the middle hepatic vein at its caval confluence: minimesohepatectomy. Ann Surg. 2010;251(1):33-9. doi: 10.1097/ SLA.0b013e3181b61db9.

7. Torzilli G, Palmisano A, Del Fabbro D, Marconi M, Donadon M, Spinelli A, et al. Contrast-enhanced intraoperative ultrasonography during surgery for hepatocellular carcinoma in liver cirrhosis: is it useful or useless? A prospective cohort study of our experience. Ann Surg Oncol. 2007;14(4):1347-55. Epub 2007 Jan 26.

8. Torzilli G, Montorsi M, Del Fabbro D, Palmisano A, Donadon M, Makuuchi M. Ultrasonographically guided surgical approach to liver tumours involving the hepatic veins close to the caval confluence. $\mathrm{Br}$ J Surg. 2006;93(10):1238-46.

9. Donadon M, Costa G, Gatti A, Torzilli G. Thoracoabdominal approach in liver surgery: how, when, and why. Updates Surg. 2014;66(2):121-5. doi: 10.1007/s13304-013-0244-x. Epub 2013 Dec 12.

10. Torzilli G. Ultrasound-Guided Liver Surgery: An Atlas. Milan: Springer-Verlag; 2014.

11. Donadon M, Procopio F, Torzilli G. Tailoring the area of hepatic resection using inflow and outflow modulation. World $\mathrm{J}$ Gastroenterol. 2013;19(7):1049-55. doi: 10.3748/wjg.v19.i7.1049.

12. Torzilli G. Adjucts in Hepatic resection: ultrasound and emerging guidance systems. In Jarnagin WR, ed. Blumgart's Surgery of the Liver, Pancreas and Biliary Tract, vol. 2, 5th ed. 2012. p. 1604-1649

13. Matsui Y, Terakawa N, Satoi S, Kaibori M, Kitade H, Takai S, et al. Postoperative outcomes in patients with hepatocellular carcinomas resected with exposure of the tumor surface: clinical role of the nomargin resection. Arch Surg. 2007;142(7):596-602; discussion 603. 
14. Viganò L, Procopio F, Cimino MM, Donadon M, Gatti A, Costa G, et al. Is Tumor Detachment from Vascular Structures Equivalent to R0 Resection in Surgery for Colorectal Liver Metastases? An Observational Cohort. Ann Surg Oncol. 2016;23(4):1352-6017.

15. Torzilli G, Procopio F, Cimino M, Donadon M, Fabbro DD, Costa G, et al. Hepatic vein-sparing hepatectomy for multiple colorectal liver metastases at the caval confluence. Ann Surg Oncol. 2015;22(5): 1576

16. Makuuchi M, Hasegawa H, Yamazaki S, Takayasu K. Four new hepatectomy procedures for resection of the right hepatic vein and preservation of the inferior right hepatic vein. Surg Gynecol Obstet. 1987;164(1):68-72.

17. Torzilli G, Garancini M, Donadon M, Cimino M, Procopio F, Montorsi M. Intraoperative ultrasonographic detection of communicating veins between adjacent hepatic veins during hepatectomy for tumours at the hepatocaval confluence. Br J Surg. 2010; 97(12):1867-73. doi: 10.1002/bjs.7230. Epub 2010 Aug 26.

18. Torzilli G, Procopio F, Cimino M, Donadon M, Del Fabbro D, Costa $\mathrm{G}$, et al. Radical but conservative liver resection for large centrally located hepatocellular carcinoma: the mini upper-transversal hepatectomy. Ann Surg Oncol. 2014;21(6):1852

19. Torzilli G, Procopio F, Donadon M, Del Fabbro D, Cimino M, GarciaEtienne CA, et al. Upper trasversal hepatectomy. Ann Surg Oncol. 2012;19(11):3566. doi: 10.1245/s10434-012-2596-8. Epub 2012 Aug 15.

20. Torzilli G, Cimino M, Procopio F, Costa G, Donadon M, Del Fabbro D, et al. Conservative hepatectomy for tumors involving the middle hepatic vein and segment 1: the liver tunnel. Ann Surg Oncol. 2014; 21(8):2699. doi: 10.1245/s10434-014-3675-9. Epub 2014 Apr 11.

21. Wicherts DA, Miller R, de Haas RJ, Bitsakou G, Vibert E, Veilhan
LA, et al. Long-term results of two-stage hepatectomy for irresectable colorectal cancer liver metastases. Ann Surg. 2008; 248(6):994-1005. doi: 10.1097/SLA.0b013e3181907fd9.

22. Schadde E, Ardiles V, Robles-Campos R, Malago M, Machado M, Hernandez-Alejandro R, et al. ALPPS Registry Group: Early survival and safety of ALPPS: first report of the International ALPPS Registry. Ann Surg. 2014;260(5):829-36; discussion 836-8. doi: 10.1097/SLA.0000000000000947.

23. Torzilli G, Cimino MM. Extending the Limits of Resection for Colorectal Liver Metastases ENHANCED ONE STAGE SURGERY. J Gastrointest Surg. 2017;21(1):187-9.

24. Viganò L, Torzilli G, Cimino M, Imai K, Vibert E, Donadon M, et al. Drop-out between the two liver resections of two-stage hepatectomy. Patient selection or loss of chance? Eur J Surg Oncol. 2016;42(9): 1385-93

25. Makuuchi M, Yamazaki S, Hasegawa $\mathrm{H}$ et al. Ultrasonically guided liver surgery. Jpn J Ultrasonics in Med. 1980;7:45-4911.

26. Torzilli $G$, Makuuchi M. Ultrasound-guided finger compression in liver subsegmentectomy for hepatocellular carcinoma. Surg Endosc. 2004;18(1):136-9. Epub 2003 Nov 21.

27. Torzilli G, Procopio F, Cimino M, Del Fabbro D, Palmisano A, Donadon $\mathrm{M}$, et al. Anatomical segmental and subsegmental resection of the liver for hepatocellular carcinoma: a new approach by means of ultrasound-guided vessel compression. Ann Surg. 2010; 251(2):229-35. doi: 10.1097/SLA.0b013e3181b7fdcd.

28. Torzilli G, Procopio F, Palmisano A, Cimino M, Del Fabbro D, Donadon $\mathrm{M}$, et al. New technique for defining the right anterior section intraoperatively using ultrasound-guided finger countercompression. J Am Coll Surg. 2009;209(2):e8-11. doi: 10.1016/ j.jamcollsurg.2009.05.014. Epub 2009 Jun 25. 